\title{
Perancangan Sistem Data Hasil Belajar Murid SMA Islam Said Na'um Berbasis Java
}

\author{
Purwanti $^{1}$ \\ ${ }^{1}$ Informatika, Universitas Indraprasta, Jakarta, Indonesia \\ e-mail: ${ }^{1}$ pwanty7@gmail.com \\ Submitted Date: November $16^{\text {th }}, 2020$ \\ Revised Date: December 30 $30^{\text {th }}, 2020$ \\ Reviewed Date: December $30^{\text {th }}, 2020$
Accepted Date: January $05^{\text {th }}, 2021$
}

\begin{abstract}
SMAI Said Na'um is a senior secondary education institution in the Jakarta area. The system at this school has not used a computerized system optimally so it has several problems. The problems in Said Na'um SMAI include recording values using paper files which take a very long time. Lack of storage media, the data search process takes a little time. The information received is currently less fast and less accurate. Often there are data errors or inaccurate data in making reports. Data storage that is still in the form of physical files can cause damage to data. Based on this information, the research carried out aims to create an information system for learning assessment for students of Said Na'um Senior High School, Central Jakarta. This research was conducted by creating a data system on student learning outcomes at Said Na'um Islamic Senior High School using a Java-based programming language.
\end{abstract}

Keywords: School; High school; Islam; Information Systems; High school; Java

\begin{abstract}
Abstrak
SMAI Said Na'um merupakan suatu institusi pendidikan menengah atas yang ada di daerah Jakarta. Sistem pada sekolah ini belum menggunakan sistem komputerisasi secara optimal sehingga mempunyai beberapa kendala. Permasalahan yang ada di SMAI Said Na'um antara lain pencatatan nilai menggunakan berkas kerta yang memakan waktu sangat lama. Kurangnya media penyimpanan, proses pencarian data memerlukan waktu yang sedikit lama. Informasi yang diterima saat ini kurang cepat dan kurang akurat. Sering terjadi kesalahan data atau tidak akuratnya data dalam pembuatan laporan. Penyimpanan data yang masih berupa berkas fisik dapat menimbulkan kerusakan pada data. Berdasarkan informasi tersebut maka dalam penelitian yang dilaksanakan bertujuan membuat suatu sistem informasi penilaian pembelajaran pada siswa SMAI Said Na'um Jakarta Pusat. Penelitian ini dilaksanakan dengan membuat sistem data hasil belajar murid pada SMA Islam Said Na'um dengan menggunakan Bahasa pemrograman berbasis Java.
\end{abstract}

Kata Kunci: Sekolah; SMA; Islam; Sistem Informasi; SMA; Java

\section{Pendahuluan}

Teknologi bidang informasi sudah berkembang sangat maju dan cepat perkembangannya. Informasi hasil pengolahan dari sistem dengan teknologi yang baru terus meningkat sehingga informasi tersebut berkualitas sangat baik sesuai kebutuhan (Khotimah \& Iriani, 2014). Teknologi informasi ditujukan untuk membantu pekerjaan dengan menyediakan informasi dan melakukan berbagai tugas yang berhubungan dengan pengolahan informasi (Hanum \& Saifudin, 2019). Penggunaan media komputer sebagai sarana untuk membantu kerja di suatu organisasai dapat membantu pekerjaan dengan kapasitas sangat tinggi dengan kemempuan dan ketelitian yang tinggi.

Laporan hasil pengolahan data menjadi informasi dapat diperoleh secara cepat lengkap dan akurat (Ali \& Istanto, 2018). Suatu institusi pendidikan di mana salah satu transaksinya adalah pengolahan data nilai siswa dengan jumlah dan kompleksitas yang tidak sedikit dapat dibantu dengan teknologi komputer. Data yang diperolah dapat memperlihatkan potensi prestasi setiap siswa yang diperoleh masing-masing siswa (Arikunto, 2006). Sistem informasi data nilai siswa dilakukan 
menggunakan berkas kertas dapat menghambat kinerja karena membutuhkan waktu dalam mengolah data semua siswa dan ini tentunya menghambat kinerja sistem secara keseluruhan (Halim, 2012). Penelitian ini dilakukan untuk memperbaiki sistem yang masnual menjadi lebih baik dengan cara membuat suatu aplikasi berbasis komputerisasi. Aplikasi ini dapat memproses penilaian data siswa agar menjadi lebih efektif dan efisien.

Berdasarkan uraian di atas maka peneliti berupaya untuk mengadakan penelitian dengan materi yang berhubungan dengan sistem informasi penilaian pembelajaran pada siswa SMAI Said Na'um Jakarta Pusat. Dalam penelitian ini membuat suatu perancangan sistem data hasil belajar murid pada SMA Islam Said Na'um Berbasis Java. SMAI Said Na'um masih menggunakan berkas kertas dalam proses bisnisnya dan mempunyai beberapa kendala.

Permasalahan yang ada di SMAI Said $\mathrm{Na}$ 'um antara lain pencatatan nilai menggunakan berkas kertas yang memakan waktu sangat lama. Kurangnya media penyimpanan, proses pencarian data memerlukan waktu yang sedikit lama. Informasi yang diterima saat ini kurang cepat dan kurang akurat. Terdapat kesalahan data dan ketidakakuratan pembuatan laporan. Penyimpanan data yang masih berupa berkas fisik dapat menimbulkan kerusakan pada data.

Penelitian ini umtuk dam pembahasan yang terlalu luas dalam ruang lingkup sistem penginputan inilai yang ada di SMAI Said Na' Um, maka pada perancangan sistem yang kami buat di SMAI Said Na'um Jakarta Pusat hanya meliputi proses penginputan nilai, absensi dan pencetakan hasil belajar (raport), Laporan Siswa Perkelas, Laporan Rekapitulasi Absen, Laporan Nilai Siswa. Program aplikasi diharapkan dapat mencakup kegiatan - kegiatan seperti menginput Nilai Tugas, Nilai Ulangan Tengah Semester (UTS), Nilai Ulangan Akhir Semester (UAS), serta absensi.

\section{Metodologi Penelitian}

Dalam rangka menyelesaikan penelitian ini diperlukan data dan informasi yang digunakan sebagai sumber penulisan dan analisis permasalahan (Emzir, 2007). Adapun metode penelitian yang digunakan dalam penelitian ini pada tahapan pengumpulan data diperoleh dengan cara tinjauan lapangan. Peneliti mengumpulkan data yang diperoleh dari hasil penelitian langsung pada SMAI Said Na'um.
Tinjauan lapangan prosesnya dilaksanakan dalam tiga cara, yaitu wawancara, pengamatan, angket dan studi dokumen. Kegiatan wawancara dilakukan untuk mendapatkan data dan informasi dengan teknik tanya jawab pada pemilik untuk mengetahui objek penelitian (Thoha, 2003). Pengamatan dilakukan dengan melihat langsung proses memasukkan nilai dan absen menggunakan berkas kertas (Andriani, 2018). Proses pencarian data dengan angket dengan memberi pertanyaanpernyataan tertulis agar dijawab oleh responden. Proses studi dokumen dilakukan dengan meneliti berbagai macam dokumen sebagai bahan analisis (Uno, 2014). Peneliti mencari dari berbagai sumber dalam bentuk buku-buku ilmiah atau media melalui media internet maupun catatan semasa kuliah terutama yang erat hubungannya dengan topik penulisan ini.

\section{Analisa}

Merupakan suatu kegiatan pencarian data yang dibutuhkan oleh sistem yang ada. Analisa ini dilakukan dengan cara mempelajari dan mengetahui proses yang dikerjakan sistem (Dimyati, 2002). Mendeskripsikan sistem dalam hal menjelaskan masukan data yang digunakan, database yang tersedia, apa yang dilakukan sistem, dan keluaran yang dihasilkan.

Pada tahap ini dihasilkan model dari sistem yang ada, dengan menggunakan alat-alat antara lain Class Diagram.

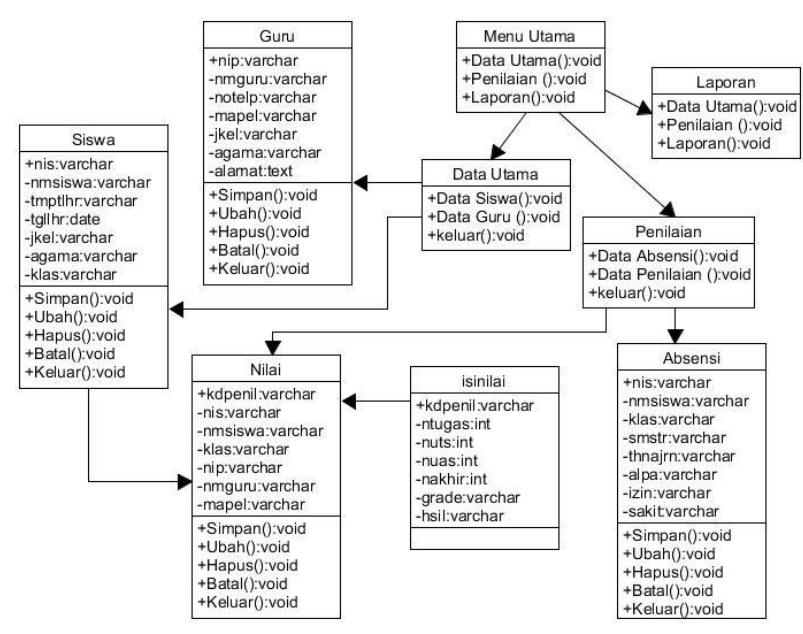

Gambar 1. Diagram Class Sistem Sekolah

Gambar 1 menjelasakan tentang nama- nama table serta atribut-atribut tanpa adanya informasiinformasi method di dalamnya. Activity Diagram merupakan diagram yang menggambarkan aktivitas atau kegiatan-kegiatan sistem yang ada. 


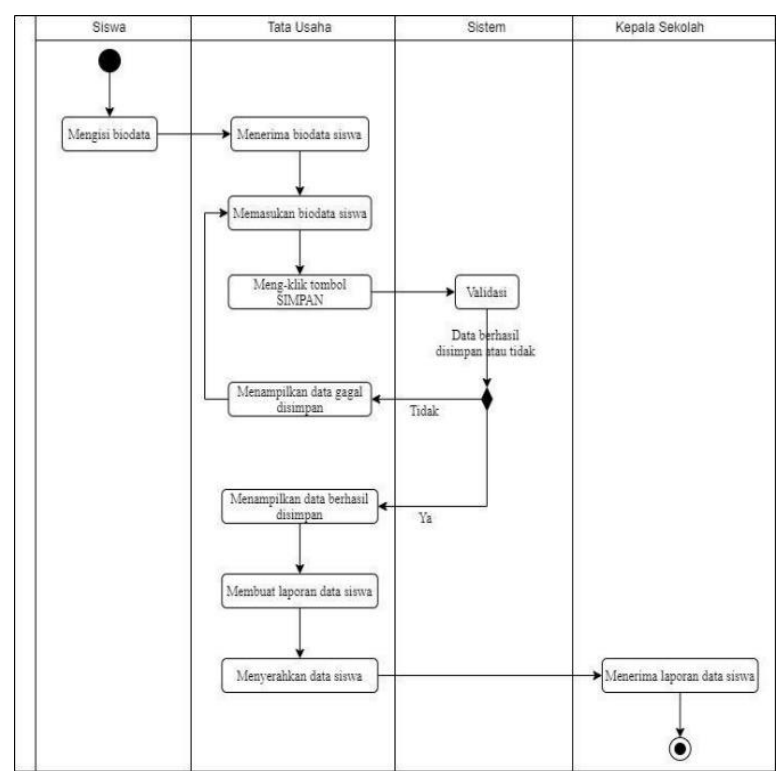

Gambar 2 Diagram Activity Siswa

Pada gambar 2 menjelaskan proses bisnis dari kegiatan yang di lakukan oleh pengguna sistem dalam hal ini adalah siswa. Siswa dapat mengolah data pada sistem seperti biodata, data matapelajaran sampai menerima data laporan nilai.

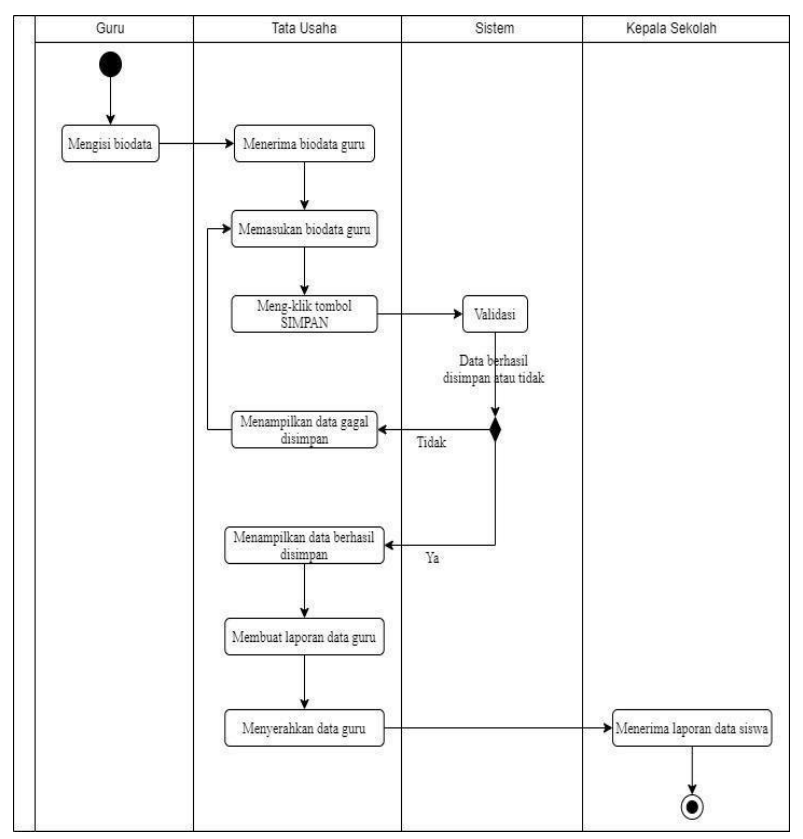

Gambar 3 Diagram Activity Guru

Pada gambar 3 dijelaskan proses bisnis dari pengguna sistem dalam hal ini adalah guru. Guru dapat melakukan pengolahan data nilai siswa melalui sistem ini secara komputerisasi. Kegiatan ini tentunya membantu tugas guru dalam mengolah data nilai siswa diproses lebih cepat dan lebih akurat.
Use Case Diagram merupakan diagram yang menjelaskan kebutuhan sistem dari posisi pengguna sistem. Sequence Diagram merupakan gambaran interaksi antarobjek dalam waktu tersusun dan berurutan.

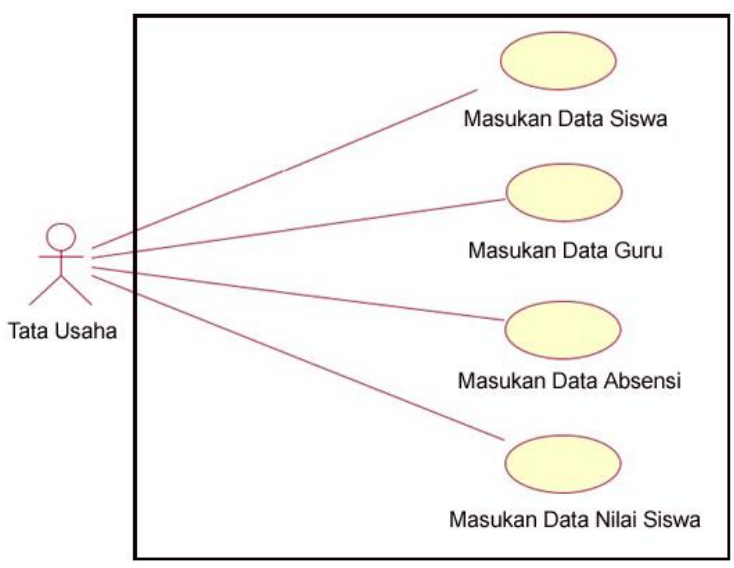

Gambar 4. Diagram Use Case Sistem Sekolah

Pada gambar 4 merupakan salah satu diagram use case yang ada menggambarkan pengguna sistam dalam hal ini adalah bagian tata usaha. Bagian tata dapat mengolah data siswa, data guru, data absensi dan data nilai.

\section{Rancangan dan Implementasi Sistem}

Perancangan Sistem merupakan tahapan merancang sistem secara detail berdasarkan proses analisa sistem, sehingga menghasilkan model sistem baru yang akan dikerjakan, dengan disertai rancangan database dan Bahasa pemrograman untuk membuat antarmuka.

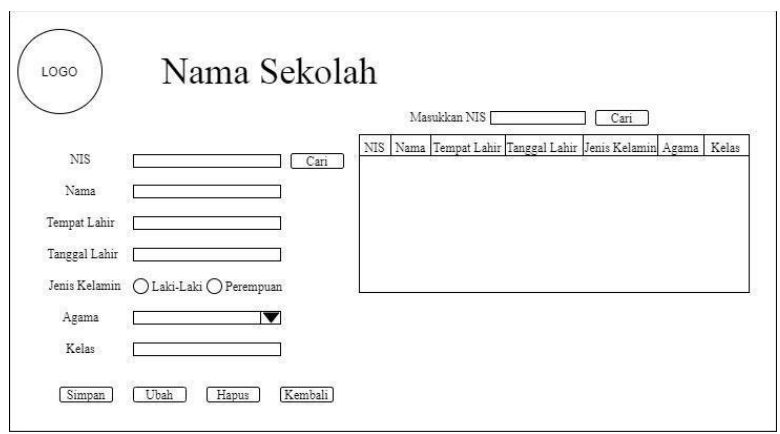

Gambar 5. Rancangan Tampilan aplikasi

Rancangan halaman utama sistam ini seperti pada gambar 5. Pada gambar tersebut menjelaskan pada aplikasi akan terdapat logo institui sekolah, form untuk inputan data-data dan tampilan tabel untuk menampilkan seluruh data yang sudah dimasukkan. 


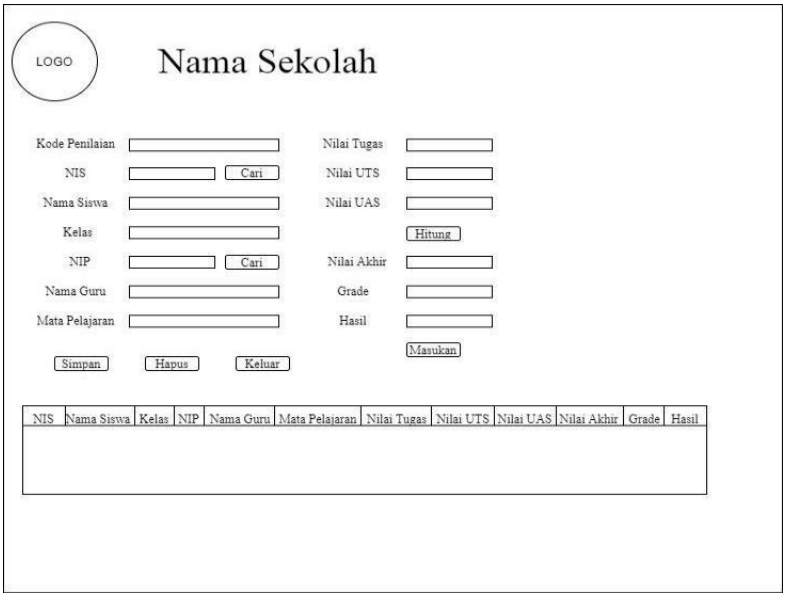

Gambar 6. Rancangan Tampilan Laporan

Gambar 6 merupakan rancangan laporan dari sistem nilai. Rancangan tampilan halaman laporan ini menampilkan data yang akan di cetak ke dalam kertas. Rancangan tampilan halaman laporan ini dibuat untuk semua data yang ada pada sistem nilai.

Tahapan implementasi dilakukan setelah rancangan seluruh proses bisnis dilakukan. Implementasi di awali dengan membuat desain dan membuat tampilan sistem dengan Bahasa pemrograman java. Berikut ini adalah bebeapa tampilan yang sudah dibuat menggunakan Bahasa pemrograman java.

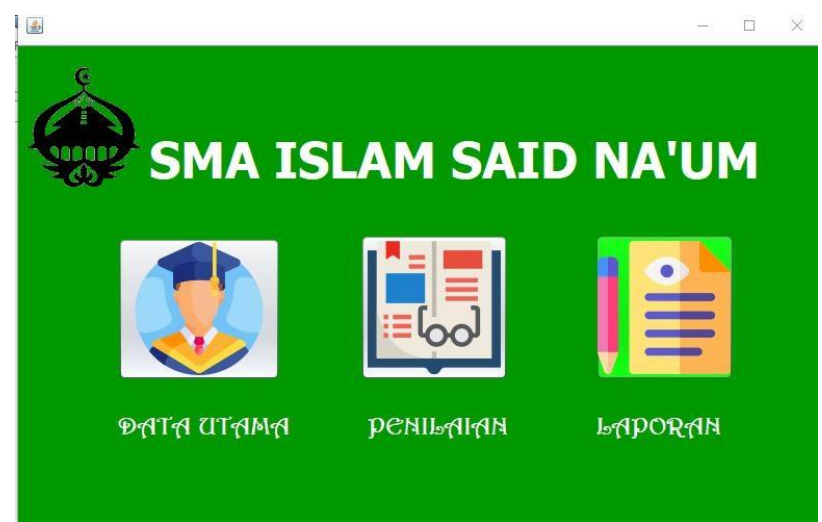

Gambar 7 Tampilan Utama Aplikasi

Pada menu utama seperti gambar 7 teridiri dari menu input data master berupa data siswa, data guru dan data laporan nilai siswa oleh guru. Pengguna harus memilih menu untuk mengolah data sesuai tampilan di halaman sistem.

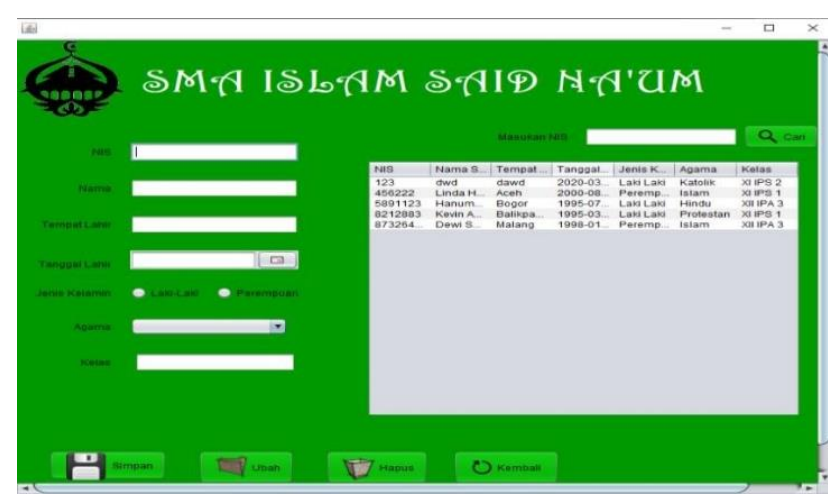

Gambar 8. Tampilan Menu Input Data

Pada gambar 8 menjelaskan tampilan berikut adalah tampilan pada saat input data ke sistem baik itu data siswa, guru dan transaksi berupa nilai siswa. Data yang sudah diinput akan tampil pada bagian tabel.

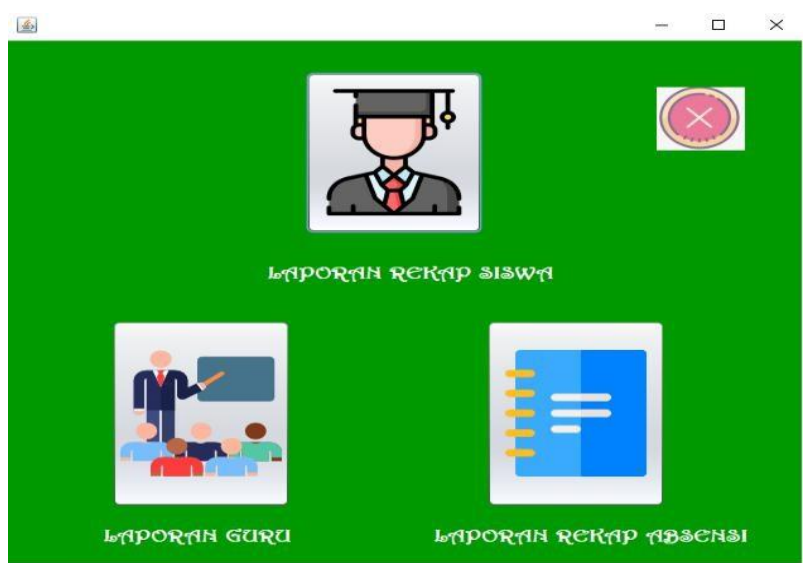

Gambar 9. Tampilan Menu Laporan

Gambar 9 menjelaskan proses pembuatan laporan hasil dari transaksi data dibuat laporan yang bisa dicetak. Data yang dicetak adalah data yang sudah diolah dan menjadi informasi yang lebih baik.

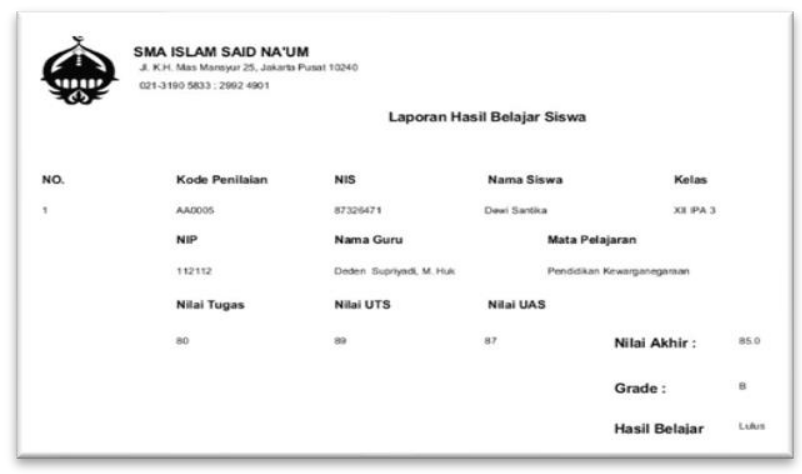

Gambar 10. Cetak Laporan 
Gambar 10 menjelasakan tampilan dari halaman laporan yang di cetak pada media percetakan seperti kertas. Sebelum dicetak ke media kertas sistem menampilakn di layar sistem untuk meyakinkan hasil cetak sudah benar.

\section{Simpulan}

Kesimpulan yang dapat diambil dari penelitian pembuatan Sistem Informasi Penilaian SMA Islam Said Na'um ini sebagai berikut:

a. Dengan adanya Sistem Informasi Penilaian, SMA Islam Said Na'um diharapkan dapat mempermudah perhitungan dan pengolahan hasil nilai akhir siswa secara cepat dan akurat.

b. Database sebagai media penyimpanan data dapat membantu pencarian data, pemelihataan data. Media penyimpanan ini menggantikan media kertas yang lebih mudah rusak dan rentan terhadap kerusakan lainnya.

c. Proses pembuatan laporan yang mengalami kesulitan dapat dilakukan secara cepat dan mudah dengan menggunakan sistem komputerisasi.

d. Proses penilaian dan pencetakan raport dapat dilakukan dengan cepat dan akurat.

\section{Saran}

Dari hasil kesimpulan yang penelitian yang dijelaskan ada beberapa saran/pertimbangan yang perlu diperhatikan dalam perancangan sistem ini, diantaranya:

a. Diperlukan pelatihan bagi pengguna sitem sehingga semua pengguna sistem dapat mengetahui cara kerja sistem secara keseluruhan.

b. Perlu adanya proses backup data untuk mengantisipasi kejadian yang mengakibatkan kerusakan database. Kegiatan backup data ini dilakukan secara periodic.

c. Pengghapusan data yang sudah tidak digunakan lagi dalam database. Kegiatan penghapusan ini bertujuan menguragi beban kirnerja perangkat lunak pengolah database.

d. Perawatan secara rutin dilakukan untuk menghindari kerusakan yang mungkin ditimbulkan pada proses transaki di database secara terus menerus.

\section{Referensi}

Ali, M., \& Istanto. (2018). Manajemen Sekolah Islam. Surakarta: Muhammadiyah Universitiy Press.

Andriani, A. (2018). Praktis Membuat Buku Kerja Guru. Sukabumi: CV Jejak.
Arikunto, S. (2006). Dasar-dasar Evaluasi Pendidikan. Jakarta: Bumi Aksara.

Dimyati, M. (2002). Belajar dan Pembelajaran. Jakarta: Rineka Cipta .

Emzir. (2007). Metodologi Penelitian Pendidikan. Jakarta: Raja Grafindo.

Halim, A. (2012). Pengaruh Strategi Pembelajaran dan Gaya Belajar Terhadap Hasil Belajar Fisika Siswa SMPN 2 Secang Kabupaten Langkat. Tabulrasa PPS UNIMED, Vol. 9 No. 2.

Hanum, W. S., \& Saifudin, A. (2019). Rancang Bangun Aplikasi Panduan Pariwisata di Kabupaten Banyuwangi Mobile Berbasis Android. Jurnal Teknologi Sistem Informasi dan Aplikasi, 2(2), 59-65. doi:10.32493/jtsi.v2i2.2798

Khotimah, A., \& Iriani, S. (2014). Sistem Informasi Nilai Siswa Pada Madrasah Tsanawiyah (MTs) Al Muhajirin Kalak Donorojo. Indonesian Journal on Networking and Security, 3(1). 4346.

Thoha, M. C. (2003). Teknik Evaluasi Pendidikan. Jakarta: PT. Raja Grafindo Persada.

Uno, H. (2014). Perencanaan Pembelajaran. Jakarta: Bumi Aksara. 